\title{
PLANEJAMENTO DE ENSINO E EDUCAÇÃO FÍSICA: uma revisão de literatura em periódicos nacionais
}

\author{
Luciana de Oliveira Nunes? \\ Denise Grosso da Fonseca \\ Cibele Biehl Bossle $e^{3}$ \\ Fabiano Bossle ${ }^{4}$
}

\section{RESUMO}

Neste estudo qualitativo objetivamos investigar como a temática planejamento de ensino vem sendo tratada na produção científica da Área de Conhecimento da Educação Física (EF). Foi realizada uma revisão de literatura em periódicos nacionais de estrato A1 a B2 do Qualis CAPES para a "Área de Avaliação Educação Física", que compreendeu o período de 2001 até 2016. Foi possível inferir que os estudos são pautados por reflexões e problematizações que enfatizam a necessidade de planejar coletivamente, a importância de vincular o planejamento à proposta do Projeto Político-Pedagógico, a coerência entre o que se planeja e a visão de sociedade e de aluno que queremos, e ainda a possibilidade que o exercício de planejar oferece no sentido de respaldar a EF como importante componente curricular. Destacamos que o planejamento participativo, embora não seja uma temática nova, vem ganhando força nos estudos encontrados, sobretudo no que se refere à participação ativa dos alunos na sua construção.

Palavras-chave: Planejamento. Educação. Artigo de Revista. Docentes.

1 Mestranda em Ciências do Movimento Humano. Professora da Rede Municipal de Ensino de Porto Alegre. Porto Alegre/Rio Grande do Sul, Brasil. E-mail: lucianaanunes@hotmail.com

2 Pós-Doutoranda em Educação. Professora da Escola de Educação Física, Fisioterapia e Dança da Universidade Federal do Rio Grande do Sul (ESEFID/UFRGS). Porto Alegre/Rio Grande do Sul, Brasil. E-mail: dgf.ez@terra.com.br

3 Pós-Doutora em Ciências do Movimento Humano. Professora do Instituto Federal de Educação, Ciência e Tecnologia do Rio Grande do Sul (IFRS). Feliz/Rio Grande do Sul, Brasil. E-mail: cibele.bossle@terra.com.br

4 Pós-Doutor em Ciências do Movimento Humano. Professor da Escola de Educação Física, Fisioterapia e Dança da Universidade Federal do Rio Grande do Sul (ESEFID/UFRGS). Porto Alegre/Rio Grande do Sul, Brasil.

E-mail: fabiano.bossle@ufrgs.br

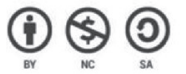

Este texto está publicado sob uma licença Creative Commons Atribuição NãoComercial-CompartilhaIgual - CC BY NC AS

Mais detalhes em: https://br.creativecommons.org/licencas/ 


\section{PLANNING TEACHING AND PHYSICAL EDUCATION: a literature review in national} journal

\section{ABSTRACT}

This qualitative study aimed to investigate the theme of education planning has been treated in the scientific production of the Knowledge Area of Physical Education (PE). It was made a reviwe in national journals literature with stratum A1 to B2 of the Qualis CAPES to the "Physical Education Evaluation Area", which covered the period 2001 to 2016. It was possible to infer that the studies are guided by reflections and problematizations that emphasize the need to plan collectively, the importance of linking planning the proposal of the political-pedagogical project, coherence between what is planned and the company's vision and student we want, and the possibility that the exercise plan offers towards to support the EF as important curricular component. We highlight that participatory planning, although not a new theme, is gaining strength in the studies found, especially as regards the active participation of students in their construction.

Keywords: Planning. Education. Review Article. Teachers.

\section{PLANIFICACIÓN DE LA ENSEÑANZA Y LA EDUCACIÓN FÍSICA: una revisión de literatura en periódicos nacionales}

\section{RESUMÉN}

Este estudio cualitativo tuvo como objetivo investigar el tema de la planificación de la educación ha sido tratado en la producción científica del área de conocimiento de Educación Física (PE). Fue realizada una revisión en revistas nacionales de la literatura estrato A1 a B2 del Qualis CAPES fue hecho a la "zona de Evaluación de la Educación Física", que abarcaba el período de 2001 a 2016. Fue posible inferir que los estudios son guiados por reflexiones y problematizaciones que enfatizan la necesidad de planificar colectivamente, la importancia de vincular la planificación de la propuesta del proyecto político-pedagógico, la coherencia entre lo que se planifican y la visión y el estudiante que queremos de la compañía, y la posibilidad de que el plan de ejercicios ofrece hacia para apoyar la EF como componente curricular importante. Destacamos que la planificación participativa, aunque no es un tema nuevo, está ganando fuerza en los estudios encontrados, especialmente en lo que se refiere a la participación activa de los estudiantes en su construcción.

Palabras clave: Planificación. Educación. Artículo de revista. Profesores. 


\section{INTRODUÇÃO}

O presente estudo de cunho qualitativo objetivou investigar como o planejamento de ensino vem sendo tratado na produção científica da área de conhecimento da Educação Física (EF). Para Menegolla (1992), o planejamento está ligado à capacidade intrínseca do homem de pensar, pois o próprio ato de pensar não deixa de ser um verdadeiro ato de planejar. Planejar de forma sofisticada e altamente científica ou ainda sem muitos esquemas e dominações técnicas, planejar por escrito, mental ou oralmente, o fato é que, segundo o autor, ninguém consegue "se livrar" do ato de planejar. Para Padilha (2001), planejar é sempre processo de reflexão, de tomada de decisão sobre a ação.

Definições e exemplos do que é planejar não faltam na literatura científica, independente da Área de Conhecimento. Gandin (1999) propõe uma série destas definições, mas a todas elas alguns pontos são comuns: decisão, organização, ação, transformação. O autor considera que o ser humano está sempre ensaiando maneiras de transformar suas ideias em realidade e que, mesmo de maneira inconsciente ou ineficaz, em todas as suas ações utiliza-se do que é essencial ao planejamento: divisar o futuro, analisar a realidade e propor ações e atitudes para transformá-la (GANDIN, 2001). O planejamento configura-se, portanto, como um instrumento de organização, de decisão para dar mais eficiência à ação humana (GANDIN, 1999).

Ora, se a necessidade de planejamento é um imperativo da vida humana, se o próprio ato de planejar é um processo educativo, justifica-se plenamente a prerrogativa de utilizar-se do planejamento no âmbito educacional e, sem dúvida, o planejamento se impõe neste setor como recurso de organização em circunstâncias onde a educação é concebida como fator de mudança, renovação e progresso (TURRA et al., 1991). Vasconcellos (2008) atribui ao planejamento a possibilidade de (re)significação do trabalho docente, o resgate do sentido da ação educativa, partindo de uma intencionalidade das ações a que se propõe.

Segundo Menegolla (1992), a educação na condição de processo jamais pode ser desenvolvida isoladamente, ou seja, todo o processo educacional requer um planejamento em termos nacionais, estaduais, regionais e comunitários, além de um planejamento em nível de escola e outro específico de ensino, relacionado às diferentes disciplinas e conteúdos. Destarte, o planejamento educacional organiza-se da seguinte forma: i) Planejamento do sistema de educação: tem como pressuposto básico o delineamento da filosofia da educação do País; ii) Planejamento da escola: é o que entendemos por Projeto Político- Pedagógico; iii) Planejamento curricular: definido por Turra et al. (1991, p.17) como "previsão global e sistemática de toda a ação a ser desencadeada pela escola, em consonância com os objetivos educacionais, tendo por foco o aluno", de tal modo que, através dos diferentes componentes curriculares, o processo ensino-aprendizagem seja favorecido; iv) Planejamento de ensino: prevê as situações específicas do professor junto aos alunos.

Embora sirva como instrumento norteador da intervenção pedagógica, prevendo objetivos, conteúdos e métodos atrelados às exigências da realidade social e às condições socioculturais e individuais dos alunos, na prática o distanciamento entre as intenções e as 
ações colocam o planejamento num território de incertezas e controvérsias. O planejamento de ensino no âmbito escolar há algum tempo parece ter submergido em uma crise de identidade e validade (VASCONCELLOS, 2008). É possível perceber o reiterado questionamento acerca da "falência" do planejamento como importante instrumento no processo educativo, seja pela abordagem tecnicista, desarticulada do todo social, ou pela redução à ação burocrática a qual ficou relegado. Vasconcellos (2008) já apontava na primeira edição de seu livro, em 1995, para certo desprezo pelo tema no interior da academia em se tratando de produção científica, um "vazio cultural". Bossle $(2002,2003)$, ao abordar a temática na EF, aponta a mesma postura dos professores da Área frente à "necessidade" deste instrumento e faz referência ao planejamento como uma questão polêmica entre os professores deste coletivo docente. A resistência em colocar no papel o que se desejava demonstrava uma descrença no planejamento de ensino por parte dos professores, que tinham no ato de planejar uma tarefa mecânica, para cumprir uma formalidade completamente sem sentido. No mesmo artigo o autor corrobora com a conclusão de Vasconcellos (2008) sobre a baixa produção na comunidade científica a respeito do tema planejamento de ensino também no âmbito da EF escolar, e a consequente necessidade de estudos que avancem nas questões referentes à prática pedagógica e à didática de ensino do licenciado em EF.

Ao tratar da necessidade de legitimação da disciplina de EF no currículo escolar, Fonseca (2015) sugere a utilização do planejamento de ensino como recurso importante para o reencontro da disciplina consigo mesma. Longe de colocá-lo numa condição redentora diante dos problemas educacionais pertinentes à $\mathrm{EF}$, a autora considera de grande valia recolocar o planejamento de ensino em destaque no processo de ensino-aprendizagem da disciplina. Bossle (2003), ao constatar um movimento de negação e descrédito do planejamento de ensino por parte dos professores de EF baseado em estudos anteriores (KUNZ, 1991, MOLINA NETO, 1996, FAGGION, 2000, SCHERER, 2000), destaca que tal negação não quer dizer que não haja planejamento, mas que os significados atribuídos a este instrumento revelam uma singularidade de sua concepção frente às demandas do cotidiano escolar.

Fonseca (2015), apoiada nas ideias de diversos autores (SOUZA, 1987, VASCONCELLOS, 1995, CORAZZA, 1997, BOSSLE, 2003, 2009), atribui essa negação a uma lacuna, um vazio que ficou entre o tecnicismo e esta nova abordagem que possibilitava a ressignificação da prática de planejar. A autora acredita que o grande desafio a ser enfrentado diz respeito ao ressignificar o planejamento e redimensionar sua abrangência como elemento importante no processo educativo. Implica, segundo Vasconcellos (2008), em resgatar sua necessidade e possibilidade. Desafio estabelecido, o fato é que o descompasso entre a necessidade intrínseca do ser humano em planejar suas ações de alguma forma, qualquer que seja, e a descrença e/ou negação de tal prática no âmbito educacional reafirma a questão: Por que planejar? Vasconcellos (2008) instiga a olhar o planejamento como prática humana contraditória, tendo lucidez de seus limites, mas também de suas potencialidades, a compreendê-lo como um instrumento teórico-metodológico poderoso, mas também falível. Sobretudo, segundo Vasconcellos (2008, p.37) é necessário compreender que "não há processo, técnica ou instrumento de planejamento que faça milagre", o que 
realmente mobiliza o ato e o sentido de planejar é o desejo de mudança da realidade e a crença na possibilidade dessa mudança.

\section{METODOLOGIA}

Com o intuito de contemplar o objetivo traçado para o presente estudo, realizamos uma revisão de literatura que partiu da revisão apresentada por Bossle (2002). Noronha e Ferreira (200) definem os estudos de revisão como aqueles que

[...] analisam a produção bibliográfica em determinada área temática, dentro de um recorte de tempo, fornecendo uma visão geral ou um relatório do estado-da-arte sobre um tópico específico, evidenciando novas ideias, métodos, subtemas que têm recebido maior ou menor ênfase na literatura selecionada (NORONHA; FERREIRA, 2000, p. 191).

A escolha do artigo de Bossle (2002) como ponto de partida da presente revisão se deu em função da análise da produção científica nacional realizada pelo referido autor, que abrangeu o período compreendido entre 1994 até o ano de 2000. O autor analisou 15 periódicos considerados, à época, como aqueles "de maior expressão no âmbito da produção científica da pesquisa em Educação Física" (BOSSLE, 2002, p. 34) e encontrou somente dois artigos sobre a temática planejamento (KREBS, 1997; CORREIA, 1996). Além disso, quatro resumos de trabalhos apresentados em grupos temáticos do X Congresso Brasileiro de Ciências do Esporte, realizado em 1997, também foram encontrados pelo referido autor.

A partir da análise desses estudos, Bossle (2002) apontou um baixo número de artigos e trabalhos sobre planejamento de ensino na área de conhecimento da $E F$, o que configurava, de acordo com o autor, certo desinteresse pela temática em detrimento de outros temas abordados em estudos desta Área. O autor assinalou ainda que reflexões sobre a necessidade e a possibilidade do planejamento na condição de importante elemento no processo educativo em contrapartida com a descrença e negação por parte dos docentes suscitava possibilidades de investimento em pesquisas e discussões até então pouco exploradas no interior da academia. Partindo dessas considerações, focamos a nossa análise na produção científica sobre planejamento de ensino do período compreendido entre 2001 e 2016 (ano da elaboração do presente estudo).

Para dar segmento à revisão a qual nos propomos, localizamos no endereço eletrônico da Coordenação de Aperfeiçoamento de Pessoal de Nível Superior (CAPES) ${ }^{6}$ os periódicos nacionais com estrato de A1 a B2 (disponíveis on-line), em interface com as

5 Os periódicos analisados por Bossle (2002) foram: Revista Mineira de EF, Revista Artus, Revista Perfil, Revista Paulista de EF, Revista Movimento, Revista Brasileira de Ciências do Esporte, Revista Motus Corporis, Revista Motriz, Revista de EF da U.E.M., Revista Kinesis, Revista Motrivivência, Revista Conexões, Revista da F.M.U., Revista Paranaense de EF, Perspectivas em EF Escolar.

6 Disponível em: < https://sucupira.capes.gov.br/sucupira/public/consultas/coleta/veiculoPublicacaoQualis/ listaConsultaGeralPeriodicos.jsf>. Acesso em: 12 abr. 2016. 
Ciências Humanas e Sociais. A justificativa para a escolha deste estrato do Qualis CAPES está em consonância com o critério de seleção do estudo de Bossle (2002), ou seja, periódicos de maior expressão. É importante destacar que os periódicos selecionados não são todos particularmente da Área da EF, mas foram cotados entre A1 e B2 pelo Qualis CAPES 2014 para "Área de Avaliação Educação Física".

Considerando os critérios mencionados selecionamos 12 periódicos especificados a seguir:

Quadro 1 - Periódicos

\begin{tabular}{|l|c|}
\hline Periódico - ISSN & $\begin{array}{c}\text { Classificação QUALIS CAPES - área de } \\
\text { avaliação Educação Física }\end{array}$ \\
\hline Movimento (1982-8918) & A2 \\
\hline Motricidade (2182-2972) & B1 \\
\hline Motriz: Revista de Educação Física (1980-6574) & B1 \\
\hline Revista Brasileira de Ciências do Esporte (2179-3255) & B1 \\
\hline Revista da Educação Física UEM (1983-3083) & B1 \\
\hline $\begin{array}{l}\text { Revista Brasileira de Educação Física e Esporte (1981- } \\
\text { 4690) }\end{array}$ & B2 \\
\hline $\begin{array}{l}\text { Interface - Comunicação, Saúde, Educação (1424- } \\
\text { 3228) }\end{array}$ & B2 \\
\hline Motrivivência UFS (2175-8042) & B2 \\
\hline Revista Brasileira de Educação Especial (1413-6538) & B2 \\
\hline Revista Pensar a Prática (1980-6183) & B2 \\
\hline $\begin{array}{l}\text { Revista Brasileira de Ciência e Movimento } \\
\text { (0103-1716) }\end{array}$ & B2 \\
\hline $\begin{array}{l}\text { Revista Brasileira de Atividade Física e Saúde } \\
\text { (1413-3482) }\end{array}$ & \\
\hline
\end{tabular}

Fonte: Qualis CAPES 2014

Definidos os periódicos, utilizamos no sistema de busca geral dos mesmos o termo "planejamento" e, em alguns casos, acrescentamos os termos "ensino" ou "planejamento de ensino" para refinar a busca. A partir da leitura dos estudos encontrados, foram elencados 17 estudos nos quais o planejamento de ensino emergiu como temática central ou como temática complementar, abordado num contexto de organização do trabalho do professor. São eles: 
Quadro 2 - Artigos Encontrados

\begin{tabular}{|c|c|c|c|}
\hline Periódico & Endereço eletrônico & $\begin{array}{l}\text { Data de } \\
\text { acesso }\end{array}$ & Artigos \\
\hline Movimento & $\begin{array}{c}\text { http://www.seer.ufrgs.br/ } \\
\text { Movimento }\end{array}$ & $12 / 04 / 2016$ & $\begin{array}{c}\text { (BOSSLE, 2002), (PALAFOX, } \\
\text { 2004), (AMARAL, 2004), (TERRA, } \\
\text { 2004), (KRAVCHYCHYN; } \\
\text { OLIVEIRA; CARDOSO, 2008), } \\
\text { (BOSSLE; MOLINA NETO, 2009), } \\
\text { (PEREIRA; MENDES (2010)). }\end{array}$ \\
\hline Motriz & $\begin{array}{c}\text { http://www.periodicos. } \\
\text { rc.biblioteca.unesp.br/index. } \\
\text { php/motriz }\end{array}$ & $12 / 04 / 2016$ & $\begin{array}{l}\text { (MENDES et al., 2010), } \\
\text { (RESENDE; SOARES; MOURA, } \\
\text { 2009) }\end{array}$ \\
\hline RBCE & $\begin{array}{l}\text { http://rbceonline.org.br/ } \\
\text { revista/index.php/RBCE }\end{array}$ & $12 / 04 / 2016$ & $\begin{array}{c}\text { (RAIMUNDO; VOTRE; TERRA, } \\
\text { 2012), (EUSSE; BRACHT; } \\
\text { ALMEIDA, 2015) }\end{array}$ \\
\hline $\begin{array}{l}\text { Revista da } \\
\text { Educação } \\
\text { Física UEM }\end{array}$ & $\begin{array}{l}\text { http://periodicos.uem.br/ojs/ } \\
\text { index.php/RevEducFis }\end{array}$ & $21 / 04 / 2016$ & $\begin{array}{c}\text { (COSTA; OLIVEIRA, 2002), } \\
\text { (RODRIGUES; DARIDO, 2008) }\end{array}$ \\
\hline $\begin{array}{l}\text { Pensar a } \\
\text { Prática }\end{array}$ & $\begin{array}{l}\text { http://www.revistas.ufg.br/ } \\
\text { index.php/fef }\end{array}$ & $21 / 04 / 2016$ & (SAYÃO; MUNIZ, 2004) \\
\hline Motrivivência & $\begin{array}{l}\text { https://periodicos.ufsc.br/ } \\
\text { index.php/motrivivencia }\end{array}$ & $12 / 04 / 2016$ & $\begin{array}{l}\text { (MEZZAROBA; COELHO; } \\
\text { CARDOSO, 2007) }\end{array}$ \\
\hline RBEFE & $\begin{array}{l}\text { http://www.revistas.usp.br/ } \\
\text { rbefe }\end{array}$ & $12 / 04 / 2016$ & $\begin{array}{l}\text { (BARROS; DARIDO, 2009), } \\
\text { (VENÂNCIO; DARIDO, 2012) }\end{array}$ \\
\hline
\end{tabular}

Após elencar os artigos encontrados que possuíam relação com a temática pesquisada, passamos para a descrição dos mesmos. O estudo de Bossle (2002), ponto de partida desta revisão, aponta para a carência de estudos e pesquisas que possibilitem refletir sobre questões didático-pedagógicas, incluindo o planejamento de ensino enquanto elemento constitutivo indispensável ao trabalho docente. Bossle (2002) propõe a possibilidade de construção de um planejamento diferente do modelo burocrático, uma concepção que reafirme sua importância no cotidiano escolar e que revele um comprometimento do professor com a sua ação educativa crítica e reflexiva, além de tornar possível a concretização de objetivos existentes nas propostas pedagógicas construídas pela escola.

Em consonância com a proposta de Bossle (2002), Mendes et al. (2010) destacam que a ação de planejar de forma consciente pode contribuir efetivamente para o reconhecimento da EF como componente curricular. Mendes et al. (2010) ressaltam a necessidade da participação dos professores da área da EF tanto na construção do Projeto Político-Pedagógico (PPP) da escola quanto na construção de uma proposta curricular da disciplina que justifique suas ações, com opções político-pedagógicas coerentes com o processo de democratização do ensino e que atenda a realidade escolar.

Palafox (2004), Terra (2004) e Amaral (2004) analisam o planejamento de ensino sob uma abordagem crítica, descrevendo uma sistemática denominada Planejamento Coletivo 
do Trabalho Pedagógico (PCTP). Palafox (2004) aborda a proposta do PCTP, em desenvolvimento desde 1993, fundamentada no princípio da formação continuada de professores de EF da Escola Básica da Universidade Federal de Uberlândia (UFU) e da Rede Pública Municipal de Ensino de Uberlândia. O PCTP tem como objetivo a elaboração de um Projeto Político-Pedagógico coletivo e passou a constituir parte de uma política interinstitucional com vistas a valorizar o componente curricular EF no sistema escolar de Uberlândia.

Terra (2004) por meio de um estudo de caso do tipo etnográfico entende o trabalho coletivo e colaborativo como uma atitude fundamental para concretizar transformações educativas almejadas no PCTP. A autora aponta que, "a partir do trabalho coletivo e colaborativo, os professores tiveram a oportunidade de aprender uns com os outros, o que me permite também refletir que o saber, enquanto processo argumentativo, comunicativo e social é de fato uma construção coletiva" (TERRA, 2004, p. 172).

O artigo de Amaral (2004) apresenta reflexões sistematizadas no PCTP amparadas em uma concepção crítica de currículo. A autora também descreve o momento histórico em que ocorreu a reunião do grupo para a construção de um projeto político para a $\mathrm{EF}$ Escolar. Amaral (2004, p. 152) acredita que é possível a construção de "um processo diferenciado de planejamento de currículo que permita a superação da prática de reprodução de pacotes prontos e/ou 'manuais didáticos', aproximando os professores da produção de saberes escolares e da conquista de sua autonomia científica e pedagógica".

No tocante à construção coletiva do planejamento em EF, Bossle e Molina Neto (2009) apresentam uma revisão bibliográfica sobre trabalho coletivo. Foi percebido pelos autores que o trabalho coletivo na EF escolar não emergia como temática principal, embora previsto em muitas Propostas Político-Pedagógicas de várias Redes de Ensino. No entanto, quando as práticas construídas por professores de EF eram analisadas, o assunto acabava por emergir no interior destas interpretações. Para os autores, percebe-se aí uma "simbiose" entre trabalho coletivo na EF e Propostas Político-Pedagógicas com vistas à horizontalização das relações da escola. Este fator somado à formação crítica de alguns pesquisadores das décadas de 1980 e 1990 e à concepção das aulas abertas (HILDEBRANDT-STRAMANN; LAGING, 1986) mencionadas pelos autores no artigo, aponta para o início de um perceber-se coletivamente na escola.

Sayão e Muniz (2004) apresentam alguns equívocos comuns em relação ao planejamento, que dificultam uma proposta de educação de qualidade, voltada à formação de um sujeito crítico e participativo. Dentre esses equívocos, os autores apontam a construção do planejamento somente no início do ano, desconsiderando sua íntima relação com a dinâmica da prática cotidiana; a construção do mesmo de forma isolada por parte do professor, fator que o desvincula de um projeto coletivo de escola, de educação e de formação; e ainda a concepção do planejamento descolada do Projeto Político-Pedagógico.

Venâncio e Darido (2012) apresentam o entendimento que um grupo de professoras de EF do Ensino Fundamental na Rede Municipal de São Paulo possuem a respeito do significado do PPP no cotidiano escolar. As autoras também intentam fornecer subsídios para a elaboração e implementação de um PPP e apontar os limites e possibilidades da ação coletiva no contexto escolar. Venâncio e Darido (2012) destacam a inserção de conteúdos 
não tradicionais como esportes radicais, natação, capoeira, conhecimentos sobre o corpo, entre outros, através do planejamento participativo com os alunos. Além de discussões sobre fenômenos que influenciam as aulas de EF, como a mídia e as questões de gênero.

Pereira e Mendes (2010) analisam as características do trabalho do professor de EF, bem como a organização do trabalho docente na disciplina em uma organização curricular que rompe com as formas tradicionais de ensino. Na apreciação sobre como os professores constroem seu planejamento e organizam suas aulas, as autoras apresentam a dificuldade do professor em estabelecer um diálogo interdisciplinar entre os conteúdos pertinentes à EF e as demandas da rede temática ${ }^{7}$. Nota-se aí a dificuldade enfrentada pelos professores não só de planejar o "o quê, o para quê e o como", mas também de relacioná-los a aspectos que extrapolam a especificidade de sua área de atuação.

Rodrigues e Darido (2008), abordam as dificuldades e alternativas na implementação de propostas baseadas nas três dimensões dos conteúdos (procedimental, conceitual e atitudinal) e fazem alusão ao planejamento coletivo num viés de compartilhamento de responsabilidade. Os autores analisam algumas abordagens, tendências e perspectivas referentes à prática educativa dos professores da área. Dentre estes "modelos" analisados surge como proposta a participação ativa dos alunos nas tomadas de decisão nas aulas, configurando um planejamento participativo que promove uma espécie de protagonismo dos mesmos em razão de se sentirem parte do processo pedagógico.

Raimundo, Votre e Terra (2012) analisam criticamente o Projeto Acelerar para Vencer (PAV) em Minas Gerais. O estudo revela o distanciamento entre os objetivos preconizados nos documentos estruturadores do projeto e o planejamento do professor de EF. Na mesma linha da proposta de Rodrigues e Darido (2008), o referido projeto previa como orientação metodológica que o professor problematizasse e inter-relacionasse as experiências trazidas pelos alunos com os conteúdos a serem ensinados. No entanto, o contexto da prática sugere uma dificuldade do professor em traduzir para o seu planejamento ações dessa perspectiva pedagógica.

Na pesquisa-ação de Kravchychyn, Oliveira e Cardoso (2008), o efetivo exercício de planejar coletivamente trouxe como resultado o reconhecimento da disciplina de EF pela comunidade escolar enquanto componente curricular do sistema educacional. Partindo da realidade revelada por Oliveira (2004) de que a EF não possui conteúdos sistematizados que indiquem o trabalho ao longo das séries, os autores propuseram um planejamento curricular baseado nos pressupostos da pedagogia histórico-crítica (GASPARIN, 2003) e organizaram reuniões de planejamento onde professores e pesquisadores discutiram e organizaram conjuntamente os conteúdos e planos de aula.

Resende, Soares e Moura (2009) fazem alusão a diferentes modelos de planejamento e estruturação das aulas de EF. Em sua pesquisa os autores propõem-se a apresentá-los e

7 Segundo as autoras, a rede temática compreende as relações entre a micro e a macroestrutura a partir de uma visão local, buscando, num movimento constante entre esses níveis, transformar a visão inicial. Trata-se de uma rede de relações dos elementos a serem trabalhados com os alunos, onde a criação, produção, elaboração e reelaboração do conhecimento se constroem através de uma multiplicidade de interações, intersecções, reversibilidades e processos. 
analisá-los partindo do princípio de que para a elaboração do planejamento e a estruturação das aulas são necessárias competências didático-pedagógicas do professor. Os resultados do estudo apontam para duas perspectivas de planejamento e estruturação de aulas: aulas estruturadas em partes compartimentalizadas e aulas planejadas de forma integrada, processual. Assinalam ainda a existência de um grupo de professores cujas atividades são desenvolvidas sem um deliberado planejamento das mesmas.

Mezzaroba, Coelho e Cardoso (2007) relatam a opção por realizar o estágio a partir da "concepção de aulas abertas às experiências" como orientação didático-pedagógica, com base na abordagem de Hildebrandt e Laging (1986). Os autores destacam que esse tipo de aula visa maior participação do aluno no planejamento, no desenvolvimento e na avaliação, descentralizando o papel do professor na elaboração das mesmas. Através da participação ativa dos alunos no processo de elaboração das aulas, os autores observaram a dificuldade dos mesmos em exercer sua autonomia. Os autores apontam ainda a importância do estabelecimento de uma melhor comunicação para a concretização do planejamento.

Barros e Darido (2009) analisam as estratégias de ensino que os professores evidenciaram em seus planejamentos, a previsão dos conteúdos, os critérios de seleção e a divisão didática dos mesmos. Os autores destacam o planejamento participativo realizado por uma professora, que parece considerá-lo não apenas "como sendo um critério de seleção de conteúdos, mas também uma estratégia de ensino de conceitos sobre a disciplina Educação Física, seus objetivos, conteúdos" (BARROS; DARIDO, 2009, p. 68).

Eusse, Bracht e Almeida (2015), na busca por uma opção diferente da oferecida pela racionalidade técnico-instrumental e à luz das reflexões de Hans George Gadamer, analisam os três grandes momentos da estrutura de uma prática pedagógica: o planejamento, a execução e a avaliação. Apoiados nas proposições de Tardif (2002), os autores destacam que o planejamento de uma aula não deve ser um momento unicamente instrumental e racional. Para os autores, o professor artista "não planeja sua obra a partir da cópia de estruturas já estipuladas ou guias. Ao contrário, reconhece que o espaço da aula será sempre

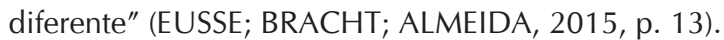

Dos artigos elencados, somente o estudo de Costa e Oliveira (2002), apresenta o tema planejamento em EF voltado para a Educação Infantil. Os autores, convictos de que EF como componente curricular na Educação Infantil tem muito a contribuir com o desenvolvimento integral da criança pré-escolar, apresentam a estruturação de uma proposta de planejamento para este nível educacional. Costa e Oliveira (2002) fundamentam seu projeto considerando o eixo movimento, previsto no Referencial Curricular Nacional para a Educação Infantil (RCNPEI) (BRASIL, 1998), como atribuição da EF.

Após a descrição dos artigos selecionados, passamos para análise e discussão sobre os mesmos.

\section{ANÁLISE E DISCUSSÃO}

A partir da análise dos artigos selecionados foi possível inferir que, de 2001 a 2016, o tema planejamento de ensino obteve algum aumento no que tange ao número 
de produções científicas. Em comparação com a revisão feita por Bossle (2002), na qual foram encontrados apenas dois artigos e quatro resumos de trabalhos sobre a temática, nos periódicos pesquisados, houve um aumento de 18 estudos, porém, se levarmos em conta que se passaram 15 anos, esse número de estudos não parece expressivo. Entretanto, considerando a descrença no planejamento no âmbito educacional, é possível considerar, com base nesta revisão de literatura, que a produção de conhecimento sobre o tema planejamento apresenta sinais de crescimento, ainda que "pelas bordas" (VASCONCELLOS, 2008).

Numa visão geral dos artigos elencados, foi possível perceber que os autores revisitam conceitos do ponto de vista da Didática. Libâneo (1994), Vasconcellos (2008), Gandin (1999), entre outros, ainda são referências que dão conta de conceituar o planejamento em Educação e seus termos adjacentes. Além disso, os estudos são pautados por reflexões e problematizações que enfatizam a necessidade de planejar coletivamente, a importância de vincular o planejamento à proposta do Projeto Político-Pedagógico, a coerência entre o que se planeja e a visão de sociedade e de aluno que queremos, e ainda a possibilidade que o exercício de planejar oferece no sentido de respaldar a EF como importante componente curricular.

Além do referido acima, uma abordagem em especial nos chamou a atenção em diversos artigos analisados na presente revisão de literatura: o planejamento participativo. Interessante notar que essa não é uma abordagem nova, um dos artigos encontrados na revisão de literatura de Bossle, Correia (1996), já tratava dessa temática. Essa abordagem de certa forma já vinha se desenhando desde os anos 1980, por meio da concepção das Aulas Abertas pensada por Hildebrandt-Stramann e Laging (1986) e apontava para o início de um perceber-se coletivamente na escola (BOSSLE; MOLINA NETO, 2009).

Por meio da análise empreendida nessa revisão de literatura, é possível apontar que o planejamento participativo vem ganhando força nos estudos encontrados. Rodrigues e Darido (2008), Bossle e Molina Neto (2009), Sayão e Muniz (2004), Resende, Soares e Moura (2009), Mezzaroba, Coelho e Cardoso (2007), Barros e Darido (2009) abordam em algum momento dos seus textos a participação ativa dos alunos no planejamento das aulas, alguns como tema principal e outros como temática complementar. É possível relacionar o planejamento participativo ao que Neira (2009) denomina de "processos de ensino abertos", cuja dinâmica valoriza o trabalho em equipe, a solidariedade do grupo e a dedicação na superação dos desafios propostos, além da experiência dos alunos, favorecendo sua participação com sugestões e ideias.

Cabe destacar que a análise realizada se refere exclusivamente aos artigos científicos encontrados e selecionados por meio da revisão de literatura empreendida para o presente estudo e não pode ser tomada como universal, pois não recobre tudo o que já foi produzido sobre a temática planejamento de ensino.

\section{CONSIDERAÇÕES FINAIS}

Este estudo objetivou investigar como o planejamento de ensino vem sendo tratado na produção científica da área de conhecimento da EF, por meio de revisão de literatura. 
A análise dos estudos encontrados nos permitiu visualizar diversas concepções que atravessam o tema planejamento de ensino encontradas nos artigos analisados, como a necessidade de planejar coletivamente, a importância de vincular o planejamento à proposta do Projeto Político-Pedagógico, a coerência entre o que se planeja e a visão de sociedade e de aluno que queremos, e ainda, a possibilidade que o exercício de planejar oferece no sentido de respaldar a EF como importante componente curricular. Dentre estas, destacamos uma em especial - o planejamento participativo, pois, apesar de não ser uma temática nova, vem ganhando força dentre as problematizações empreendidas nos artigos analisados. Tais problematizações, presentes de uma forma ou de outra nos artigos analisados na presente revisão de literatura, nos levam a refletir em que medida o tema planejamento vem avançando na literatura científica, considerando as transformações no contexto sociocultural, as novas demandas e configurações do ensino e tantas outras variáveis que redimensionam o sistema de educação atual.

É possível interpretar que, embora não faça mais sentido questionar a importância do planejamento de ensino na $\mathrm{EF}$, dado o seu caráter irrefutável como instrumento pedagógico, na prática do cotidiano escolar e pelos estudos que ora analisamos, o assunto ainda desvela uma complexidade por vezes inconveniente, difícil de desenlear tanto no trato acadêmico quanto no dia a dia do exercício docente. O tema planejamento ao ser afetado pelas problematizações já mencionadas revela certa dificuldade em lidar ou dialogar com essas questões que o atravessam, como a própria construção coletiva ou ainda o entrelaçamento entre as questões pertinentes à EF e às demandas interdisciplinares ou de caráter sociopolítico inerentes ao contexto dos alunos. Isso nos convida a refletir nas tantas vezes em que o planejamento das práticas pedagógicas do professor de EF não dialoga com um planejamento maior, quer sejam as diretrizes curriculares da disciplina ou o Projeto Político-Pedagógico da instituição. Ratifica-se desta forma a metáfora citada por Neira $(2009$, p.142) de que "a escola parece um time de futebol com bons jogadores, mas cada um trabalha sozinho e, o pior, quer fazer gol em qualquer trave".

Por fim, cabe ressaltar que os artigos ora elencados aliados à retomada de conceitos pertinentes à Didática nos convidam a olhar para o planejamento de ensino intencionalmente localizado na sua perspectiva epistemológica, pedagógica e didática (FONSECA, 2015). Pensar no planejamento a partir de sua capacidade de promover mudanças proporciona possibilidades de reflexões-ações que nos encaminham a continuar investindo nesta temática com o intuito de "(re)discutir, (re)encantar e (re)significar o fazer docente" conforme propõe Fonseca (2015).

\section{REFERÊNCIAS}

AMARAL, G.A. Planejamento de currículo na Educação Física: possibilidades de um projeto coletivo para as escolas públicas de Uberlândia/Minas Gerais. Movimento. Porto Alegre: v.10, n.1, jan./abr., 2004. 
BARROS, A.M.; DARIDO, S.C. Práticas pedagógicas de dois professores mestres em educação física escolar e o tratamento da dimensão conceitual dos conteúdos. Rev. bras. Educ. Fís. Esporte, São Paulo, v.23, n.1, jan./mar., 2009.

BOSSLE, F. Planejamento de Ensino na Educação Física: uma contribuição ao coletivo docente. Movimento. Porto Alegre: v.8, n.1, jan./abr., 2002.

. Planejamento de ensino dos professores de Educação Física do $2^{\circ}$ e $3^{\circ}$ ciclos da Rede Municipal de Ensino de Porto Alegre: um estudo do tipo etnográfico em quatro escolas desta rede de ensino. Porto Alegre: UFRGS, 2003. Dissertação (Mestrado), Escola de Educação Física, UFRGS, 2003.

. O Planejamento coletivo dos professores de Educação Física como possibilidade de construção da proposta político-pedagógica. In: MOLINA NETO et al. Quem aprende? Pesquisa e formação em Educação Física Escolar. ljuí: Editora UNIJUÍ, 2009. ; MOLINA NETO, V. Leituras para (Re)Pensar o Trabalho Coletivo dos Professores de Educação Física. Movimento. Porto Alegre: v.15, n.3, jul./set., 2009.

BRASIL. Secretaria de Educação do Ensino Fundamental. Referencial Curricular Nacional para Educação Infantil. Brasília, DF, 1998.

CORAZZA, S.M. Planejamento de ensino como estratégia de Política Cultural. In: MOREIRA, A.F.B. Currículo: questões atuais. Campinas: Papirus, 1997.

CORREIA, W.R. Planejamento Participativo e o Ensino de Educação Física no $2^{\circ}$ grau. Revista Paulista de Educação Física, São Paulo: supl. 2, 1996.

COSTA, J.C.K.; OLIVEIRA, A.A.B. O eixo movimento na Educação Infantil: uma proposta de planejamento. Revista da Educação Física UEM. Maringá: v.13, n.1, 2002.

EUSSE, K.L.G.; BRACHT, V.; ALMEIDA, F.Q. A prática pedagógica como obra de arte: Aproximações à estética do professor-artista. RBCE, v.38. n.1., jan./mar., 2016.

FAGGION, C.A. A Prática Docente dos Professores de Educação Física do Ensino Médio das Escolas Públicas de Caxias do Sul. Porto Alegre: 2000. (Mestrado em Ciências do Movimento Humano) Escola de Educação Física, UFRGS, 2000.

FONSECA, D.G. Planejamento. In: FONSECA, Denise Grosso da; MACHADO, Roseli Belmonte. (orgs). Educação Física: (re)visitando a didática. Porto Alegre: Sulina, 2015. GANDIN, D. Planejamento como Prática Educativa. 10ª Edição. São Paulo: Loyola, 1999. . A posição do planejamento participativo entre as ferramentas de intervenção na realidade. Currículo sem Fronteiras, v.1, n.1, jan./jun., 2001.

GASPARIN, J. L. Uma didática para a pedagogia Histórico-Crítica. Campinas, SP: Autores Associados, 2003.

HILDEBRANDT-STRAMANN, R.; LAGING, R. Concepções Abertas no Ensino de Educação Física. Rio de Janeiro: Ao Livro Técnico, 1986.

KRAVCHYCHYN, C.; OLIVEIRA, A.A.B; CARDOSO, S.M.M.V. Implantação de uma proposta de sistematização e desenvolvimento da educação física no Ensino Médio. Movimento. Porto Alegre: v.14, n.2, mai./ago., 2008.

KREBS, R.J. Considerações Organizacionais para o Planejamento Efetivo de uma Aula. Revista Metropolitana de Ciências do Movimento Humano/Faculdades Metropolitanas Unidas - F.M.U., n. 3, 1997. 
KUNZ, E. Educação Física: Ensino e Mudanças. Ijuí: UNIJUÍ, 1991.

LIBÂNEO, J.C. Didática. São Paulo: Cortez, 1994.

MENDES, M.I.B.S. et al. Reflexões sobre o fazer pedagógico da Educação Física. Motriz.

Rio Claro: v.16, n.1, jan./mar., 2010.

MENEGOLLA, M. Por que planejar? Como planejar?: currículo-área-aula. Petrópolis: Vozes, 1992.

MEZZAROBA, C.; COELHO, G.F.M.; CARDOSO, C.L. Planejar/ministrar 'aulas abertas' no

Ensino Médio: uma experiência de ensino em turma mista de voleibol. Motrivivência, ano XIX, n.28, jul., 2007.

MOLINA NETO, V. La Cultura Docente Del Profesorado de Educación Física de Las

Escuelas Públicas de Porto Alegre. Barcelona, 1996. (Doutorado). Departamento de Educación de La Universidad de Barcelona. España, 1996.

NEIRA, M.G. Educação Física: desenvolvendo competências. São Paulo: Phorte, 2009.

OLIVEIRA, A. A. B. Planejando a Educação Física Escolar. In: VIEIRA, J. L. L. (Org). Educação

Física e Esportes: estudos e proposições. Maringá: EDUEM, 2004.

PADILHA, P.R. Planejamento dialógico: como construir o projeto político-pedagógico da escola. São Paulo: Cortez; Instituto Paulo Freire, 2001.

PALAFOX, G.H.M. Planejamento coletivo do trabalho pedagógico da Educação Física PCTP/EF como sistemática de formação continuada de professores: a experiência de Uberlândia. Movimento. Porto Alegre: v.10, n.1, jan./abr., 2004.

PEREIRA, N.; MENDES, V. A Educação Física organizada na escola por ciclos de formação: especificidades do trabalho docente. Movimento. Porto Alegre: v.16, n.3, jul./set., 2010.

RAIMUNDO, A.C.; VOTRE, S.J.; TERRA, D.V. Planejamento Curricular da Educação Física no projeto de correção do fluxo escolar. RBCE, Florianópolis: v.34, n.4, out./dez., 2012.

RESENDE, H.G.; SOARES, A.J.G.; MOURA, D.L. Caracterização dos modelos de estruturação das aulas de educação física. Motriz. Rio Claro: v.15, n.1, jan./mar., 2009.

RODRIGUES, H.A.; DARIDO, S.C. As três dimensões dos conteúdos na prática pedagógica de uma professora de Educação Física com mestrado: um estudo de caso. Revista da Educação Física UEM., Maringá: v.19, n.1, 2008.

SAYÃO, M.N.; MUNIZ, N.L. O planejamento na Educação Física Escolar: um possível caminho para a formação do novo homem. Pensar a Prática. Goiás: v.7, n.4, jul./ dez., 2004.

SCHERER, A. O Conhecimento Pedagógico do Professor de Educação Física na Escola Pública da Rede Estadual de Ensino e sua Relação com a Prática Docente. Porto Alegre: UFRGS, 2000. (Mestrado em Ciências do Movimento Humano) Escola de Educação Física, UFRGS, 2000.

SOUZA, M.I. A farsa do planejamento: fazem-se muitos planos, mas pouco se planeja.

Tecnologia Educacional. Rio de Janeiro: v.16, n.77, jul./ago., 1987.

TARDIF, M. Saberes docentes e formação profissional. Petrópolis: Vozes; 2002.

TERRA, D.V. Orientação do trabalho colaborativo na construção do saber docente: a perspectiva do planejamento coletivo do trabalho pedagógico (PCTP). Movimento. Porto Alegre: v.10, n.1, jan./abr., 2004. 
TURRA, C.M.G. et al. Planejamento de Ensino e Avaliação. $11^{\text {a }}$ Edição. Porto Alegre: Sagra, 1991.

VASCONCELLOS, C.S. Planejamento: projeto de ensino-aprendizagem e projeto políticopedagógico. São Paulo: Libertad, 2008.

VENÂNCIO, L.; DARIDO, S.C. A educação física escolar e o projeto político pedagógico: um processo de construção coletiva a partir da pesquisa-ação. Rev. bras. Educ. Fís. Esporte, São Paulo, v.26, n.1, jan./mar., 2012.

Recebido em: junho/2016 Aprovado em: outubro/2016 